\title{
Cross-Coupling Reactions of Alkyl Halides with Aryl Grignard Reagents Using a Tetrachloroferrate with an Innocent Countercation
}

\author{
Toru Hashimoto, ${ }^{\mathrm{a}, *}$ Tsubasa Maruyama, ${ }^{\mathrm{a}}$ Takamichi Yamaguchi, ${ }^{\mathrm{a}}$ \\ Yutaka Matsubara, ${ }^{a}$ and Yoshitaka Yamaguchi ${ }^{\mathrm{a}, *}$ \\ a Department of Advanced Materials Chemistry, Graduate School of Engineering, Yokohama National University, 79-5 \\ Tokiwadai, Hodogaya-ku, Yokohama 240-8501, Japan \\ Phone:(+81)-45-339-3932 \\ Fax: $(+81)-45-339-3932$ \\ E-mail: hashimoto-toru-kh@ynu.ac.jp; yamaguchi-yoshitaka-hw@ynu.ac.jp
}

Manuscript received: May 7, 2019; Revised manuscript received: July 16, 2019;

Version of record online:

Supporting information for this article is available on the WWW under https://doi.org/10.1002/adsc.201900568

\begin{abstract}
Bis(triphenylphosphoranylidene)
ammonium tetrachloroferrate, (PPN) $\left[\mathrm{FeCl}_{4}\right]$ (1), was evaluated as a catalyst for cross-coupling reactions. 1 exhibits high stability toward air and moisture and is an effective catalyst for the reaction of secondary alkyl halides with aryl Grignard reagents. The PPN cation is considered as an innocent counterpart to the iron center. We have developed an easy-to-handle iron catalyst for "ligand-free" cross-coupling reactions.
\end{abstract}

Keywords: Iron; ferrate salt; cross-coupling reaction; alkyl halide; Grignard reagent

Transition-metal-catalyzed cross-coupling reactions between organic electrophiles and organometallic reagents represent one of the most powerful strategies for the construction of carbon-carbon bonds. ${ }^{[1]}$ Since the discovery of cross-coupling reactions, palladium and nickel complexes have been extensively studied as catalysts, and continuous improvements have resulted in the development of highly efficient catalytic systems. Considerable attention has also been focused on the use of iron catalysts in these reactions, given that iron is an ideally suited practical transition metal owing to its low cost, low toxicity, and abundance. ${ }^{[2]}$ The first discovery of $\mathrm{FeCl}_{3}$-catalyzed cross-coupling reactions was reported by Kochi in $1971 .^{[3]}$ In 1998, Cahiez used an iron/NMP $(\mathrm{NMP}=N$-methylpyrrolidinone) system, in which NMP serves as a cosolvent that has a beneficial impact on reactions involving alkenyl electrophiles. ${ }^{[4]}$ Subsequently, Fürst- ner improved this $\mathrm{Fe}(\mathrm{acac})_{3} / \mathrm{NMP}$ ( $\mathrm{acac}=2$,4-pentanedionato) system for reactions using aryl chlorides and triflates. ${ }^{[5,6]}$

So far, various catalyst systems have been developed combining iron sources such as $\mathrm{FeCl}_{3}$ and $\mathrm{Fe}$ $(\mathrm{acac})_{3}$ with donor molecules such as amines, ${ }^{[7]}$ phosphines, ${ }^{[7 \mathrm{~h}, 8]}$ or $N$-heterocyclic carbenes $(\mathrm{NHCs})^{[8 \mathrm{8}, 9,10]}$ as ligands and/or additives. ${ }^{[11]}$ In addition, well-defined iron complexes also have been developed as catalysts for the coupling reactions.$^{[7 \mathrm{~h}-\mathrm{j}, 8 \mathrm{~b}-\mathrm{i}, \mathrm{d} \mathrm{d}-\mathrm{g}, 11 \mathrm{e}, \mathrm{g}]}$ Moreover, it has been reported that $\mathrm{Fe}(\mathrm{acac})_{3}$ itself acts as an effective catalyst for the coupling reactions. $\mathrm{Fe}(\mathrm{acac})_{3}$ is commercially available and stable toward air and moisture. It is thus an easyto-handle iron source for the preparation of iron complexes and catalysts. While $\mathrm{FeCl}_{3}$ is arguably one of the most basic iron sources, it is unfortunately hydroscopic. Therefore, the development of easy-tohandle iron sources for large-scale industrial processes remains highly desirable.

Iron-containing imidazolium salts, generally classified as ionic liquids, show high stability toward air and moisture. In addition, these salts act as efficient catalysts for cross-coupling reactions. ${ }^{[12,13]}$ In these catalytic systems, the formation of iron-NHC species as the catalytically active species by in-situ deprotonation of the azolium cation with a Grignard reagent cannot be ruled out. ${ }^{[8,9,9,10]}$ Therefore, we were interested in the development of easy-to-handle iron catalysts and the realization of "ligand-free" iron catalysis for cross-coupling reactions. Herein, we report the cross-coupling of alkyl halides with aryl Grignard reagents catalyzed by (PPN) $\left[\mathrm{FeCl}_{4}\right]$ (1), i.e., a tetrachloroferrate bearing the innocent cation bis 


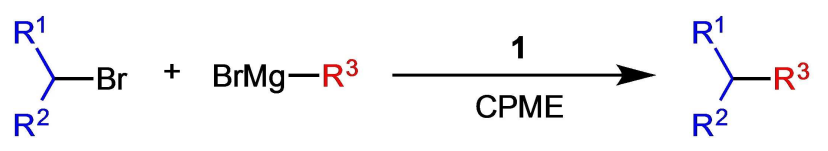

Scheme 1. The cross-coupling reactions catalyzed by (PPN) $\left[\mathrm{FeCl}_{4}\right](\mathbf{1})$ reported in this work.

$$
\begin{aligned}
& \left(\begin{array}{c}
N_{N}^{\prime \prime} \mathrm{PPh}_{3} \\
\mathrm{PPh}_{3}
\end{array}\right) \mathrm{Cl}+\mathrm{FeCl}_{3} \underset{\mathrm{MeOH}, \mathrm{rt}}{\longrightarrow}\left(\stackrel{\mathrm{PPh}_{3}}{\stackrel{\mathrm{PPh}_{3}}{\prime \prime}}\right)\left[\mathrm{FeCl}_{4}\right] \\
& \text { 1, } 91 \%
\end{aligned}
$$

Scheme 2. Preparation of catalyst (PPN) $\left[\mathrm{FeCl}_{4}\right]$ (1).

(triphenylphosphoranylidene)ammonium

(PPN), (Scheme 1).

Tetrachloroferrate $\mathbf{1}$ was prepared according to a literature method, ${ }^{[14]}$ i.e., by treating anhydrous $\mathrm{FeCl}_{3}$ with an equimolar amount of bis(triphenylphosphoranylidene)ammonium chloride $((\mathrm{PPN}) \mathrm{Cl})$ in $\mathrm{MeOH}$ at room temperature. Salt 1 was obtained in $91 \%$ yield as a yellow solid (Scheme 2) and characterized by elemental analyses and X-ray diffraction study (Figure 1). Interestingly, $\mathbf{1}$ is not hydroscopic and is highly stable toward air and atmospheric moisture. ${ }^{[15,16]}$ Moreover, 1 showed good solubility in THF and NMP, whereas it was poorly soluble in ethereal solvents such as $\mathrm{Et}_{2} \mathrm{O}$, tert-butyl methyl ether (MTBE), 1,2-dimethoxyethane (DME), and cyclopentyl methyl ether (CPME).

In order to evaluate the catalytic activity of 1 , the cross-coupling reaction of bromocyclohexane (2a) with 1.2 equivalents of phenylmagnesium bromide was

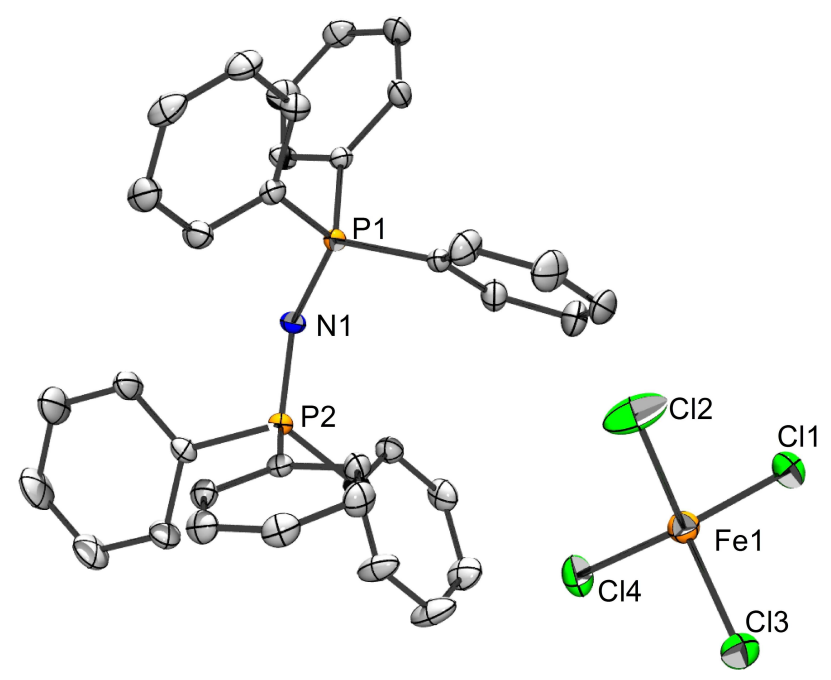

Figure 1. ORTEP drawing of (PPN) $\left[\mathrm{FeCl}_{4}\right]$ (1) with thermal ellipsoids at $30 \%$ probability. All hydrogen atoms have been omitted for clarity.
Table 1. Optimization of the conditions for the cross-coupling of bromocyclohexane (2a) with phenylmagnesium bromide

\begin{tabular}{|c|c|c|c|c|}
\hline & 2a & 2 equiv) & & $3 a$ \\
\hline Entry & Solvent & $3 \mathbf{a}(\%)^{[\mathrm{b}]}$ & Biphenyl $(\%)^{[\mathrm{c}]}$ & $\begin{array}{l}\text { Recovery } \\
\text { of } 2 \mathbf{a}(\%)\end{array}$ \\
\hline 1 & THF & 26 & 36 & 33 \\
\hline 2 & THF/NMP ${ }^{[\mathrm{d}]}$ & 27 & 17 & 55 \\
\hline 3 & NMP & 22 & 14 & 58 \\
\hline 4 & $\mathrm{Et}_{2} \mathrm{O}$ & 58 & 25 & 12 \\
\hline 5 & MTBE & 28 & 22 & 56 \\
\hline 6 & DME & 34 & 38 & 38 \\
\hline 7 & CPME & 94 & 10 & 0 \\
\hline $8^{[\mathrm{e}]}$ & CPME & 88 & 11 & 0 \\
\hline
\end{tabular}
catalyzed by $1 .^{[a]}$

[a] The reaction was carried out using 2 a $(0.5-1.0 \mathrm{mmol})$ and $\mathrm{PhMgBr}(0.6-1.2 \mathrm{mmol}, 1.2$ equiv.) in the presence of $\mathbf{1}$ (5 $\mathrm{mol} \%)$ at room temperature.

${ }^{[b]}$ The yield of $\mathbf{3} \mathbf{a}$ is based on $\mathbf{2} \mathbf{a}$ and was determined by gasliquid chromatography (GLC) analysis using undecane as the internal standard.

[c] The yield of biphenyl is based on $\mathrm{PhMgBr}$ and was determined by GLC analysis using undecane as the internal standard.

[d] $\mathrm{THF} / \mathrm{NMP}=9 / 1(\mathrm{v} / \mathrm{v})$.

${ }^{\text {[e] }}$ The reaction $(7.0 \mathrm{mmol}$ scale of $\mathbf{2} \mathbf{a})$ was carried out for $1.5 \mathrm{~h}$ using $1 \mathrm{~mol} \%$ of $\mathbf{1}$.

carried out in the presence of $5 \mathrm{~mol} \%$ of $\mathbf{1}$ in various solvents (Table 1). In the case of THF, the crosscoupled product, phenylcyclohexane (3a), was obtained in $26 \%$ yield, together with the homo-coupled product from phenylmagnesium bromide (biphenyl) in $36 \%$ yield (entry 1 ). In this case, $33 \%$ of the starting material (2 a) was recovered. When the mixed solvent THF/NMP $(9 / 1 ; \mathrm{v} / \mathrm{v})$ was used, 3a was obtained in $27 \%$ yield (entry 2). Using NMP as the solvent furnished $\mathbf{3}$ a in $22 \%$ yield (entry 3 ). Subsequently, we investigated the reaction using the aforementioned ethereal solvents, albeit $\mathbf{1}$ is poorly soluble in these solvents. In $\mathrm{Et}_{2} \mathrm{O}$, the yield of $\mathbf{3 a}$ increased to $58 \%$ yield, but the reaction did not reach completion (entry 4). MTBE and DME were not suitable solvents, i.e., 3 a was obtained merely in low yield $(28 \%$ and $34 \%$; entries 5 and 6). As shown in entry 7, CPME provided the best results, affording $3 \mathbf{a}$ in $94 \%$ yield together with small amounts of biphenyl (10\% yield based on $\mathrm{PhMgBr}$ ). This catalytic protocol based on $\mathbf{1}$ was also successful on the gram-scale $(7 \mathrm{mmol}$ of $\mathbf{2}$ a). In this case, the reaction proceeded efficiently to give $\mathbf{3} \mathbf{a}$ in $88 \%$ yield, even when the amount of $\mathbf{1}$ was reduced to $1 \mathrm{~mol} \%$ (entry 8 ).

To demonstrate the efficiency of $\mathbf{1}$ as a catalyst for such cross-coupling reactions, we investigated the 
substrate scope with a variety of alkyl halides and aryl Grignard reagents under the optimized reaction conditions, and the results are summarized in Table 2. Using $p$-tolylmagnesium bromide, $\mathbf{3} \mathbf{b}$ was obtained in 95\% yield (entry 1). $p$-Methoxyphenylmagnesium bromide afforded $\mathbf{3 c}$ in $90 \%$ yield (entry 2), while $p$ dimethylaminophenylmagnesium bromide furnished a slightly lower yield of $\mathbf{3 ~ d}(78 \%$, entry 3$)$. $p$-Fluorophenylmagnesium bromide, which bears an electron-withdrawing substituent, afforded $3 \mathrm{e}$ in $63 \%$ yield (entry 4). Next, we investigated the influence of different electrophiles. The reaction between iodocyclohexane (2 b) and $\mathrm{PhMgBr}$ furnished $3 \mathbf{a}$ in $69 \%$ yield (entry 5 ). In the case of chlorocyclohexane ( $\mathbf{2} \mathbf{c})$, the yield of $\mathbf{3 a}$ decreased to $41 \%$ (entry 6). Bromocycloheptane (2 d) was also tolerated as a coupling partner, affording $\mathbf{3 f}$ in $50 \%$ yield (entry 7). The reaction of acyclic alkyl bromide $\mathbf{2}$ e generated $\mathbf{3} \mathbf{g}$ in $81 \%$ yield, whereas the iodo analogue $\mathbf{2} \mathbf{f}$ provided $\mathbf{3 g}$ in $53 \%$ yield (entries 8 and 9). As shown in entry 10, the siloxy substituent on the alkyl chain remained intact and the product was obtained in $72 \%$ yield. $o$-Tolylmagnesium bromide

Table 2. Substrate scope of the cross-coupling reaction of alkyl halides with aryl Grignard reagents catalyzed by $1{ }^{\text {[a] }}$

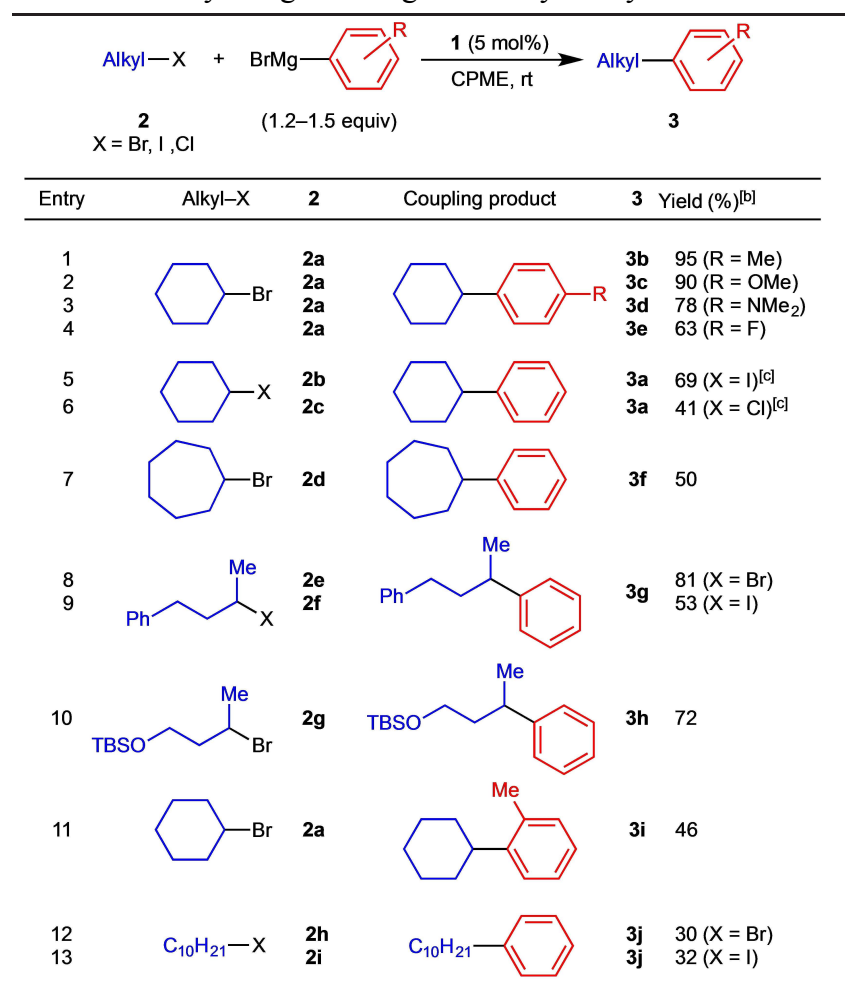

${ }^{[a]}$ The reaction was carried out using alkyl halides $2(0.5-$ $1.0 \mathrm{mmol})$ and an aryl Grignard reagent (1.2-1.5 equiv.) in the presence of $1(5 \mathrm{~mol} \%)$ at room temperature.

${ }^{[b]}$ Isolated yield.

${ }^{[c]}$ The yield of $\mathbf{3} \mathbf{a}$ is based on $\mathbf{2} \mathbf{b}$ or $\mathbf{2} \mathbf{c}$ and was determined by GLC analysis using undecane as the internal standard. gave the corresponding product $\mathbf{3 i}$ in moderate yield ${ }^{[\mathrm{hh}]}$ (entry 11). We next examined the reaction with primary alkyl halides. The reaction using 1-bromodecane $(\mathbf{2} \mathbf{h})$ proceeded sluggishly to give coupling product $\mathbf{3} \mathbf{j}$ in $30 \%$ yield under concomitant formation of decane $(15 \%)$ and 1-decene $(40 \%)$. Furthermore, $15 \%$ of bromide $\mathbf{2 h}$ was recovered (entry 12 ). In the case of 1-iododecane (2i), the corresponding product $(3 \mathrm{j})$ was obtained in $32 \%$ yield. ${ }^{[17]}$ Moreover, benzylmagnesium bromide furnished $\mathbf{3} \mathbf{k}$ in $75 \%$ yield (Scheme 3). ${ }^{[8 b, g-i]}$

To gain insight into the reaction mechanism, ${ }^{[18]}$ we investigated the coupling reaction using trans-4benzyloxycyclohexyl bromide (2j) and (bromomethyl) cyclopropane (2 k) as electrophiles under standard conditions (Schemes 4 and 5). Treatment of $\mathbf{2} \mathbf{j}$ with $\mathrm{PhMgBr}$ afforded a mixture of stereoisomers $\mathbf{3 1}$ in $69 \%$ yield (trans:cis $=74: 26$ ). In the case of $2 \mathbf{k}$, the simple coupled product $\mathbf{3} \mathbf{m}$ was not detected, whereas ring-opened product $3 \mathbf{n}$ was obtained in $13 \%$ yield. Overall, these results indicated that the cross-coupling reaction catalyzed by $\mathbf{1}$ likely involves radical species. ${ }^{[7 b, 8 a, c, e, g]}$

Furthermore, we examined the isolation of any potentially formed iron species. However, all attempts to obtain such species were unsuccessful. Although the actual structure of the intermediates in our catalytic system is not clear at this point, we assume that the $\left[\mathrm{FeCl}_{4}\right]^{-}$anion of 1 plays an important role in the

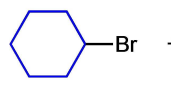

$2 \mathbf{a}$

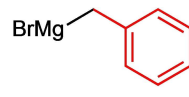

(1.5 equiv)

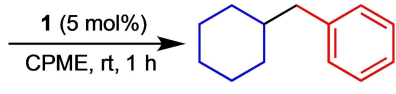

$3 \mathbf{3 k}, 75 \%$
Scheme 3. Coupling reaction of $\mathbf{2}$ a with benzylmagnesium bromide catalyzed by $\mathbf{1}$.

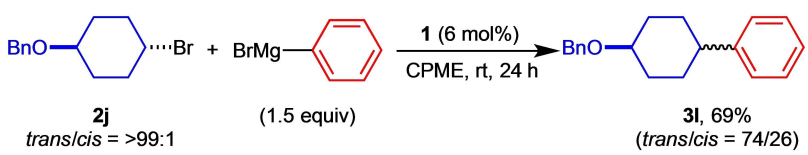

Scheme 4. Coupling reaction of $\mathbf{2} \mathbf{j}$ with $\mathrm{PhMgBr}$ catalyzed by 1.

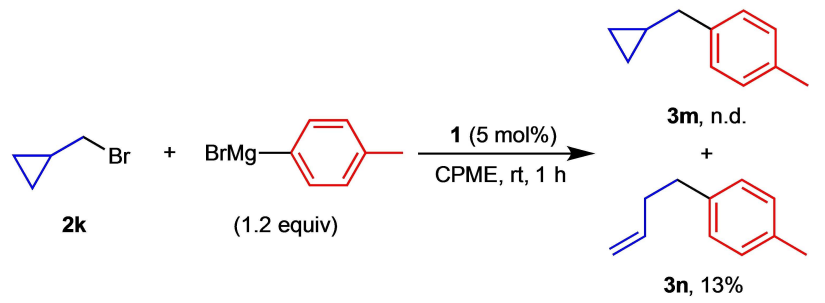

Scheme 5. Coupling reaction of $\mathbf{2} \mathbf{k}$ with $\mathrm{PhMgBr}$ catalyzed by 1: radical clock experiment. 


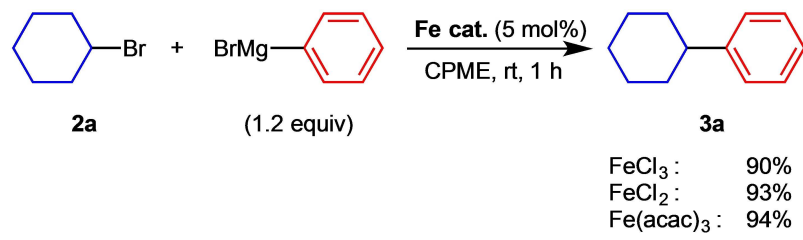

Scheme 6. Cross-coupling reactions using iron salts in CPME.

catalytic cycle. When other iron salts such as $\mathrm{FeCl}_{3}$, $\mathrm{FeCl}_{2}$, or $\mathrm{Fe}(\mathrm{acac})_{3}$ were employed as catalysts under otherwise identical reaction conditions, the coupled product 3 a was obtained in $90 \%, 93 \%$, and $94 \%$ yield, respectively (Scheme 6). These results indicate that both 1 and these other iron compounds afford similarly active iron species via the reduction of a Grignard reagent in the catalytic cycle. Accordingly, we assume that the PPN cation in $\mathbf{1}$ does not engage in the catalytic reaction, i.e., the PPN cation can be considered as an innocent counterpart to the iron center.

In conclusion, we have reported (PPN) $\left[\mathrm{FeCl}_{4}\right]$ (1) as an efficient catalyst for the coupling reactions of secondary alkyl halides with aryl and benzyl Grignard reagents under mild reaction conditions. 1 exhibits high stability toward air and atmospheric moisture. The results described in this paper may thus promote the development of "ligand-free" iron-catalyzed reactions. Further investigations into the (i) mechanistic aspects of this catalytic system, including the role of the countercation, ferrate, and the solvent, (ii) the coupling of various organometallic reagents with organic electrophiles, and (iii) the development of novel organic transformations are currently in progress in our group.

\section{Experimental Section}

Preparation for (PPN) $\left[\mathrm{FeCl}_{4}\right]$ (1): A Schlenk tube was charged with anhydrous $\mathrm{FeCl}_{3}(0.608 \mathrm{~g}, 3.75 \mathrm{mmol})$, bis (triphenylphosphoranylidene)ammonium chloride ((PPN)Cl, $2.18 \mathrm{~g}, 3.80 \mathrm{mmol})$ and dry $\mathrm{MeOH}(45 \mathrm{~mL})$ at room temperature. After stirring overnight, the solvent was removed in vacuo to give a yellow residue that was washed with $\mathrm{Et}_{2} \mathrm{O}(4 \times$ $10 \mathrm{~mL}$ ) and dissolved in THF $(20 \mathrm{~mL})$. The solution was filtered through a pad of Celite and concentrated in vacuo. The residue was washed with hexane to give $\mathbf{1}$ as a yellow solid (2.50 g, 91\%). IR (Diamond-ATR, neat): 2359, 1436, 1264, 1182, 1112, 1027, 997, 720, 688, 530, 495, $373 \mathrm{~cm}^{-1}$. Anal. calcd for $\mathrm{C}_{36} \mathrm{H}_{30} \mathrm{Cl}_{4} \mathrm{FeNP}_{2}, \mathrm{C}, 58.73 ; \mathrm{H}, 4.11 ; \mathrm{N}, 1.90$, found $\mathrm{C}$, $58.74 ; \mathrm{H}, 4.12 ; \mathrm{N}, 1.84$.

General procedure for the cross-coupling reactions: A Schlenk tube was charged with $1(5 \mathrm{~mol} \%)$, CPME $(5 \mathrm{~mL})$, the respective alkyl halide $(0.50 \mathrm{mmol})$, and a Grignard reagent (1.2-1.5 equiv.) at room temperature. The coupling reaction was carried out at room temperature for 1-24 h. After quenching with $\mathrm{HCl}(1 \mathrm{M}, 2.0 \mathrm{~mL})$, the aqueous layer was extracted with
$\mathrm{Et}_{2} \mathrm{O}(5 \times 3 \mathrm{~mL})$. The combined organic layers were washed with brine $(5 \mathrm{~mL})$ and dried over anhydrous $\mathrm{MgSO}_{4}$. After filtration and removal of all volatiles from the filtrate, the residue was purified by column chromatography on silica gel.

\section{Acknowledgements}

This work was supported by a Chugai Award in Synthetic Organic Chemistry, Japan, and JSPS KAKENHI grant JP17K05805. This work was also supported by the Collaborative Research Program of the Institute for Chemical Research, Kyoto University (grant 2018-24). The authors are grateful to Mr. Shinji Ishihara (Yokohama Natl. Univ.) for carrying out the elemental analyses and Dr. Takahiro Iwamoto and Prof. Masaharu Nakamura (Kyoto Univ.) for their kind help with the HRMS measurements. We thank Zeon Co., Ltd. for their generous donation of CPME. We also thank Hokko Chemical Industry Co., Ltd. for the generous supply of 4-fluorophenylmagnesium bromide.

\section{References}

[1] Metal-Catalyzed Cross-Coupling Reactions, 2nd ed. (Eds.; A. de Meijere, F. Diederich), Wiley-VCH: Weinheim, 2004).

[2] For reviews, see: a) C. Bolm, J. Legros, J. L. Paih, L. Zani, Chem. Rev. 2004, 104, 6217-6254; b) B. D. Sherry, A. Fürstner, Acc. Chem. Res. 2008, 41, 1500-1511; c) W. M. Czaplik, M. Mayer, J. Cvengros, A. J. von Wangelin, ChemSusChem 2009, 2, 396-417; d) R. Jana, T. P. Pathak, M. S. Sigman, Chem. Rev. 2011, 111, 1417-1492; e) A. Fürstner, ACS Cent. Sci. 2016, 2, 778789. f) A. Piontek, E. Bisz, M. Szostak, Angew. Chem. 2018, 130, 11284-11297; Angew. Chem. Int. Ed. 2018, 57, 11116-11128.

[3] a) M. Tamura, J. K. Kochi, J. Am. Chem. Soc. 1971, 93, 1487-1489; b) S. M. Neumann, J. K. Kochi, J. Org. Chem. 1975, 40, 599-606; c) R. S. Smith, J. K. Kochi, J. Org. Chem. 1976, 41, 502-509.

[4] G. Cahiez, H. Avedissian, Synthesis 1998, 1199-1205.

[5] a) A. Fürstner, A. Leitner, Angew. Chem. 2002, 114, 632-635; Angew. Chem. Int. Ed. 2002, 41, 609-612; b) A. Fürstner, A. Leitner, M. Méndez, H. Krause, J. Am. Chem. Soc. 2002, 124, 13856-13863; c) A. Fürstner, H. Krause, C. W. Lehmann, Angew. Chem. 2006, 118, 454458; Angew. Chem. Int. Ed. 2006, 45, 440-444.

[6] It has been reported that NMP can interact with the magnesium centers in iron-catalyzed cross-coupling reactions; for details, see: S. B. Muñoz III, S. L. Daifuku, J. D. Sears, T. M. Baker, S. H. Carpenter, W. W. Brennessel, M. L. Neidig, Angew. Chem. 2018, 130, 6606-6610; Angew. Chem. Int. Ed. 2018, 57, 6496-6500.

[7] a) M. Nakamura, K. Matsuo, S. Ito, E. Nakamura, J. Am. Chem. Soc. 2004, 126, 3686-3687; b) R. B. Bedford, D. W. Bruce, R. M. Frost, M. Hird, Chem. Commun. 2005, 4161-4163; c) G. Cahiez, V. Habiak, C. Duplais, A. Moyeux, Angew. Chem. 2007, 119, 4442-4444; 
Angew. Chem. Int. Ed. 2007, 46, 4364-4366.; d) A. Guérinot, S. Reymond, J. Cossy, Angew. Chem. 2007, 119, 6641-6644; Angew. Chem. Int. Ed. 2007, 46, 65216524.; e) S. Ito, Y. Fujiwara, E. Nakamura, M. Nakamura, Org. Lett. 2009, 11, 4306-4309; f) T. Hatakeyama, N. Nakagawa, M. Nakamura, Org. Lett. 2009, 11, 44964499; g) S. E. Denmark, A. J. Cresswell, J. Org. Chem. 2013, 78, 12593-12628; h) C.-L. Sun, H. Krause, A. Fürstner, Adv. Synth. Catal. 2014, 356, 1281-1291; i) R. B. Bedford, P. B. Brenner, D. Elorriaga, J. N. Harvey, J. Nunn, Dalton Trans. 2016, 45, 15811-15817; j) Y. Matsubara, T. Yamaguchi, T. Hashimoto, Y. Yamaguchi, Polyhedron, 2017, 128, 198-202.

[8] a) R. B. Bedford, M. Betham, D. W. Bruce, A. A. Danopoulos, R. M. Frost, M. Hird, J. Org. Chem. 2006, 71, 1104-1110; b) R. B. Bedford, M. Huwe, M. C. Wilkinson, Chem. Commun. 2009, 600-602; c) T. Hatakeyama, Y. Kondo, Y. Fujiwara, H. Takaya, S. Ito, E. Nakamura, M. Nakamura, Chem. Commun. 2009, 1216-1218; d) R. B. Bedford, M. A. Hall, G. R. Hodges, M. Huwe, M. C. Wilkinson, Chem. Commun. 2009, 6430-6432; e) T. Hatakeyama, Y. Fujiwara, Y. Okada, T. Itoh, T. Hashimoto, S. Kawamura, K. Ogata, H. Takaya, M. Nakamura, Chem. Lett. 2011, 40, 1030-1032; f) S. Kawamura, T. Kawabata, K. Ishizuka, M. Nakamura, Chem. Commun. 2012, 48, 9376-9378; g) T. Hatakeyama, T. Hashimoto, Y. Kondo, Y. Fujiwara, H. Seike, H. Takaya, Y. Tamada, T. Ono, M. Nakamura, J. Am. Chem. Soc. 2010, 132, 10674-10676; h) R. B. Bedford, P. B. Brenner, E. Carter, T. W. Carvell, P. M. Cogswell, T. Gallagher, J. N. Harvey, D. M. Murphy, E. C. Neeve, J. Nunn, D. R. Pye, Chem. Eur. J. 2014, 20, 7935-7938; i) R. B. Bedford, P. B. Brenner, E. Carter, J. Clifton, P. M. Cogswell, N. J. Gower, M. F. Haddow, J. N. Harvey, J. A. Kehl, D. M. Murphy, E. C. Neeve, M. L. Neidig, J. Nunn, B. E. R. Snyder, J. Taylor, Organometallics 2014, 33, 5767-5780; j) M. Jin, L. Adak, M. Nakamura, J. Am. Chem. Soc. 2015, 137, 7128-7134; k) T. Iwamoto, C. Okuzono, L. Adak, M. Jin, M. Nakamura, Chem. Commun. 2019, 55, 1128-1131.

[9] a) S. K. Ghorai, M. Jin, T. Hatakeyama, M. Nakamura, Org. Lett. 2012, 14, 1066-1069; b) Z. Mo, Q. Zhang, L. Deng, Organometallics 2012, 31, 6518-6521; c) R. Agata, T. Iwamoto, N. Nakagawa, K. Isozaki, T. Hatakeyama, H. Takaya, M. Nakamura, Synthesis 2015, 47, 1733-1740; d) Y. Liu, J. Xiao, L. Wang, Y. Song, L. Deng, Organometallics 2015, 34, 599-605; e) X. Wang, J. Zhang, L. Wang, L. Deng, Organometallics 2015, 34, 2775-2782; f) J. A. Przyojski, K. P. Veggeberg, H. D. Arman, Z. J. Tonzetich, ACS Catal. 2015, 5, 5938-5946; g) S. B. Muñoz III, V. E. Fleischauer, W. W. Brennessel, M. L. Neidig, Organometallics 2018, 37, 3093-3101.

[10] a) T. Hatakeyama, M. Nakamura, J. Am. Chem. Soc. 2007, 129, 9844-9845; b) T. Hatakeyama, S. Hashimoto, K. Ishizuka, M. Nakamura, J. Am. Chem. Soc. 2009, 131, 11949-11963; c) Y.-Y. Chua, H. A. Duong, Chem.
Commun. 2014, 50, 8424-8427; d) Y.-Y. Chua, H. A. Duong, Chem. Commun. 2016, 52, 1466-1469.

[11] a) T. Nagano, T. Hayashi, Org. Lett. 2004, 6, 1297-1299; b) R. B. Bedford, D. W. Bruce, R. M. Frost, J. W. Goodby, M. Hird, Chem. Commun. 2004, 2822-2823; c) R. Martin, A. Fürstner, Angew. Chem. 2004, 116, 40454047; Angew. Chem. Int. Ed. 2004, 43, 3955-3957; d) A. Fürstner, R. Martin, H. Krause, G. Seidel, R. Goddard, C. W. Lehmann, J. Am. Chem. Soc. 2008, 130, 87738787; e) Y. Yamaguchi, H. Ando, M. Nagaya, H. Hinago, T. Ito, M. Asami, Chem. Lett. 2011, 40, 983-985; f) M. Jin, M. Nakamura, Chem. Lett. 2011, 40, 1012-1014; g) G. Bauer, C. W. Cheung, X. Hu, Synthesis 2015, 47, 1726-1732.

[12] K. Bica, P. Gaertner, Org. Lett. 2006, 8, 733-735.

[13] a) H.-H. Gao, C.-H. Yan, X.-P. Tao, Y. Xia, H.-M. Sun, Q. Shen, Y. Zhang, Organometallics 2010, 29, 41894192; b) C.-H. Yan, L.-L. Wang, H.-H. Gao, H.-M. Sun, Q. Shen, Chin. Sci. Bull. 2012, 57, 1953-1958; c) H.-N. Deng, T.-L. Xing, C.-L. Xia, H.-M. Sun, Q. Shen, Y. Zhang, Dalton Trans. 2012, 41, 11597-11607; d) Y. Xia, C.-H. Yan, Z. Li, H.-H. Gao, H.-M. Sun, Q. Shen, Y. Zhang, Chin. Sci. Bull. 2013, 58, 493-499; e) L.-L. Wang, B. Lu, A.-D. Zhu, H.-M. Sun, Q. Shen, Chin. Sci. Bull. 2013, 58, 3624-3629; f) C.-L. Xia, C.-F. Xie, Y.-F. Wu, H.-M. Sun, Q. Shen, Y. Zhang, Org. Biomol. Chem. 2013, 11, 8135-8144.

[14] G. P. Algra, S. Balt, Inorg. Chem. 1981, 20, 1102-1106.

[15] For details, see the Supporting Information.

[16] The crystallographic data can be obtained free of charge from The Cambridge Crystallographic Data Centre under reference number CCSC 1893663.

[17] In this reaction, decane (20\%) and 1-decene (31\%) were formed, while iodide $\mathbf{2} \mathbf{i}$ was recovered in $17 \%$.

[18] For recent mechanistic studies on iron-catalyzed crosscoupling reactions of alkyl halides, see: a) D. Noda, Y. Sunada, T. Hatakeyama, M. Nakamura, H. Nagashima, J. Am. Chem. Soc. 2009, 131, 6078-6079; b) R. B. Bedford, P. B. Brenner, E. Carter, P. M. Cogswell. M. F. Haddow, J. N. Harvey, D. M. Murphy, J. Nunn, C. H. Woodall, Angew. Chem. 2014, 126, 1835-1839; Angew. Chem. Int. Ed. 2014, 53, 1804-1808; c) J. D. Sears, P. G. N. Neate, M. L. Neidig, J. Am. Chem. Soc. 2018, 140, 11872-11883; d) S. L. Daifuku, M. H. Al-Afyouni, B. E. R. Snyder, J. L. Kneebone, M. L. Neidig, J. Am. Chem. Soc. 2014, 136, 9132-9143; e) S. L. Daifuku, J. L. Kneebone, B. E. R. Snyder, M. L. Neidig, J. Am. Chem. Soc. 2015, 137, 11432-11444; f) H. Takaya, S. Nakajima, N. Nakagawa, K. Isozaki, T. Iwamoto, R. Imayoshi, N. J. Gower, L. Adak, T. Hatakeyama, T. Honma, M. Takagaki, Y. Sunada, H. Nagashima, D. Hashizume, O. Takahashi, M. Nakamura, Bull. Chem. Soc. Jpn. 2015, 88, 410-418, and the references cited therein. 


\section{COMMUNICATIONS}

Cross-Coupling Reactions of Alkyl Halides with Aryl Grignard Reagents Using a Tetrachloroferrate with an Innocent Countercation

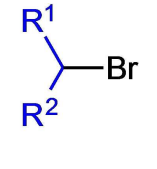

Adv. Synth. Catal. 2019, 361, 1-6

T. Hashimoto*, T. Maruyama, T. Yamaguchi, Y. Matsubara, Y. Yamaguchi*

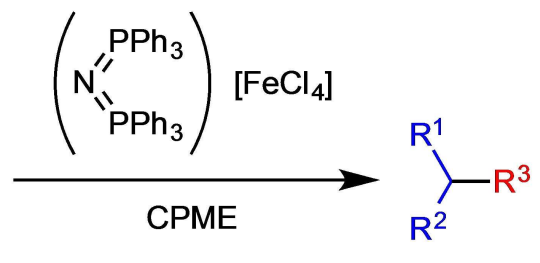

$\mathrm{R}^{3}=$ Aryl, $\mathrm{Bn} \quad$ up to $95 \%$

- Air- and moisture stable salt - Mild reaction conditions

- Easy preparation

- Radical pathway 